$\mathrm{Na}$ verdade não nos faltam bons escritores. O que nos falta é a antiga certeza de que o sujeito "é dono de seu Verbo".8 Falta-nos ainda uma terminologia crítica capaz de descrever a literatura pós-moderna. Os críticos certamente não ignoram nem silenciam esta geração de artistas, e os artistas continuam fazendo o que sempre fizeram - disparam à frente de seus intérpretes enquanto estes buscam as palavras para descrever o que eles pensam que os escritores escreveram. ${ }^{9}$

\title{
RELECTURA DESDE UNA CRÍTICA FEMINISTA DE ISIDORA AGUIRRE: DRAMATURGA CHILENA PERENNE
}

Sara del Carmen Rojo de la Rosa

UFMG

REFERÊNCIAS BIBLIOGRÁFICAS

ASSUNCĀ0, Leiloh. 0 segredo da olmo de ouro. Sõo Poulo: Progroma Morketing Teotrol, 1983. (1" versāo "Ópera rock") BRANDAO, Ruth Silviono. 0 conto do cisne (monuscrita do outoro).

DóRIA, Gustavo. Moderno teatho brosilieiro: crônnica de suas roizes. Rio de Janeiro: Servico Nacional de Teatro, 1975.

ELLIOT, Emory. Contemporary omericon fiction: an inside norrative. Riverside: University of Colifornia, 1991.

GOMES, Paulo Emilio Solles. Cinema: trojetório do subdesenvolvimento. In: Argumento, Rio de Joneiro, n. 1, p. 64, out. 1973.

HUTCHEÓN, Lindo. Poético do pós-modernismo: historia, teorio, fiç̧āo. Rio de Joneiro; Imogo. 1991.

RESUMO

Este artigo discute as características 


\section{Introducción}

Isidora Aguirre nació en 1928 y durante su vida estudió Servicio social, Pedagogía en francés, Baile, Música, Dibujo, Cine y Teatro; ha trabajado como Profesora de dramaturgia y Directora, pero principalmente ha escrito mucho y en diversos estilos: comedias livianas de carácter sicológico, Carolina; piezas folklóricas construidas como musicales, $L a$ pérgola de las flores; obras infantiles con carácter farsesco, Don Anacleto avaro; piezas con técnica e intencionalidad brechtiana, Los papeleros. Esta incansable escritora ha incursionado en la narrativa, Doy por vivido todo to soñado y en el ensayo teatral con su trabajo inédito que presentó en el Congreso de Dramaturgia Femenina de Buffalo (1988). En este texto plantea la importancia que tiene la realidad social en su escritura: "In my country, Chile, a woman playwright, in gathering her themes from the reality in which she is inmersed, will discover as a priority that which in general terms, I will call social justice."' Podemos postular, no sólo por sus palabras sino que por los signos contextuales presentes en sus textos, que su literatura en todos los períodos y en todas sus formas se ha caracterizado por su contingencia político-social.

Por otra parte, Isidora Aguirre ha afirmado que: "ser autor dramático es un duro oficio de hombre en comparación con los otros géneros literarios que desahogan" e incluso ha dicho "En el teatro creo que no hay diferencia entre la escritura femenina y masculina; en la novela sí porque allí estoy yo. En el teatro se retrata la realidad y se transforma...en lo que actúo como mujer es en mi optimismo casi utópico". ${ }^{2}$ Pienso que al definir al teatro como " un duro oficio de hombre", Isidora Aguirre se mantiene dentro del sistema patriarcal que asigna determinados roles y sentimientos para determinados géneros y que lo mismo sucede cuando cataloga su optimismo como una derivación de su condición de mujer. Me parece más acertado decir que es su horizonte de experiencias femenino unido a su técnica de observación es lo que le ha permitido entender desde dentro algunos de sus personajes femeninos como la Guatona Romilia o Rosario y que su lenguaje teatral se caracterizaría por una búsqueda de un emisor andrógino.

1. AGUIRRE, 1988. p. 1.

2. AGUIRRE, 1990

\section{Carolina}

Pieza en un acto estrenada en 1955 por el Teatro de la Universidad de Chile y estructurada en base a una situación absurda que se origina en el miedo que siente una mujer de enfrentar sus olvidos frente a su marido, en este caso el de una olla encendida antes de viajar. La situación nos remite contextualmente a la condición de sumisión de la mujer latinoamericana y a su expresión en base al silencio.

Ambos personajes, lo mismo que el estudiante, son prototípicos de la clase media tradicional de nuestras sociedades: ella, insegura, temerosa, olvidadiza; él, fuerte, dominante, seguro y el estudiante, conquistador, relajado, libre. La situación que viven se patentiza no sólo en lo que dicen, sino en el léxico, en el tono y en el modo de enunciación: ella, "Sí Carlos...; no, Carlos", él, "-Cuándo van a aprender las mujeres a viajar con lo necesario!" ${ }^{3}$ De esta manera la caracterización se modaliza en la vacilación (...) y en el énfasis (!!). Siendo este modo de enunciar y sus marcas en el texto lo que determinan el tono liviano y humorístico de la pieza.. A este tono contribuyen el tipo de palabras que emplea cada personaje y la construcción estereotipada de los mismos.

El juego de equívocos presenta los peligros que encierra una relación de poder al interior de la pareja y su consecuente incomunicación (el estudiante entrará a solucionar el problema y se encontrará con las trampas colocadas por el marido, que antes de salir apagó la llave del gas). El discurso vacilante e inseguro de la mujer tiene consecuencias concretas en la acción dramática; en otros términos sus actos de habla, que no desean ser perlocutorios se convierten, por la ausencia de intención, en intencionales.

Esta pieza muestra críticamente al personaje femenino: Carolina no tiene ninguna capacidad, ni siquiera frente al posible riesgo de muerte del estudiante, de enfrentar las situaciones; su único modo de comunicarse con los hombres es a través de su debilidad y belleza, que al estudiante lo lleva a protegerla y al marido a decidir por ella. Su frase final termina confirmando al lector esta imagen: "No sé, Carlos..."
3. AGUIRRE, C, 1970, p. 55.

4. Op. cit. p. 74. 
Disponível em http://www.letras.ufmg.br/poslit

Desconstruyendo el texto observamos que este estereotipo de sumisión se rompe cuando Carolina saliendo de su estructura clásica es capaz de hablar con el estudiante, pero también vemos que vuelve a su dependencia en la última frase que sintetiza el macrosigno de la pieza.

\section{Los papeleros}

Esta pieza, escrita en 1963 y publicada en 1964, es una obra brechtiana que pretende educar al público haciéndolo reflexionar sobre la explotación y condiciones subhumanas de vida de los seres que recogen basura. Se aspira a que el público reflexione sobre las alternativas que le ofrece la sociedad a los papeleros y cuál de ellas les permitiría iniciar un camino hacia la transformación de su existencia. Elena Castedo afirma en El teatro chileno de mediados del siglo XX que el tema de la lucha sindical ya fue tratado por Dinka Villaroel en Campamentos (1945). Lo que significa que antes de Isidora Aguirre la mujer ya se había incorporado, a través de la escritura, a la reflexión social.

La utilización de un narrador, las canciones, los títulos en escena y el uso de coros son algunos elementos de la técnica brechtiana usados por Isidora Aguirre en esta obra. A ellos se une una severa observación de personajes para la creación de caracteres persuasivos. Carlos Solorzano plantea que:

El nombre de Isidora Aguirre tiene un relieve singular. Su permanente esfuerzo por convertir al teatro en una voz amplificada, a la manera de Brecht, capaz de someter a crisis todas las estructuras sociales, las formas de conviviencia en la sociedad burguesa, la ha llevado a encontrar diversas maneras de expresión escénica. ${ }^{5}$

El personaje más interesante de esta pieza es el de la Guatona Romilia, quien al ver como su hijo se ha vuelto ladrón producto de la marginalidad, transforma su carácter imprimiéndose una energía de lucha político-social. Su fuerza proviene de su condición de madre. Es, quizás, el personaje femenino más sólido de la dramaturgia de Isidora Aguirre; pues es uno de los pocos, que se rebela ante los golpes masculinos: y exige los mismos derechos en todos los planos: "ya me cansé que el hombre llegue curado todas las noches y a manotones con una". ${ }^{6}$ La energía social de la guatona Romilia la dignifica ante sí misma, le permite canalizar su frustración personal (tiene relaciones amorosas destructivas, es incapaz de acariciar a su hijo) y dar un sentido trascendente a su rabia. Hay en esta pieza una evolución consciente en la caracterización de la fuerza femenina: una adolescente, madre postiza de un niño abandinado, se rebela ante su enamorado para no dejarlo en un hospicio. Podemos decir, entonces, que hay, desde Carolina una evolución hacia caracteres femeninos más profundos, sin que por ello haya un lugar de enunciación intencionalmente femenino. Me parece fundamental tratar el problema de la violencia ejercida sobre la mujer, pues sabemos que todos los días en América Latina, y en el mundo, aparecen informaciones sobre diversos tipos de maltratos sufridos por mujeres en la calle o al interior de sus propios hogares.

En cuanto al lenguaje observamos en esta pieza un estudio del "habla" de los diferentes sectores sociales. Lo mismo que en Carolina, no importa lo que se dice, sino como se dice. El enunciado da cuenta de un determinado contexto social; el tipo de léxico y tono establecen las intenciones de los componentes del discurso. Desde el punto de vista del lugar de enunciación el "habla" marginal se ubica en la calle; la culta, presente en las canciones, se ubica alrededor de la tesis; en tanto que el "habla" del portero del hospicio está dentro del sistema y la moral imperante.

\section{Los que van quedando en el camino}

Esta pieza fue estrenada en 1969 por el teatro de la Universidad Católica con música de Luis Advis. Según Volodia Teitelbom está estructurada como:

Un drama social apto para ser representado en la plaza. Agitador y político en el sentido brechtiano (...) Lección de una iniquidad tremenda que clama más que al cielo, a la tierra para los que la trabajan.'

El texto parte con las palabras del Che Guevara extraídas de $L a$ guerra revolucionaria, que se constituyen en una anáfora en tanto son
6. AGUIRRE, 1986. p. 37.

7. TETTELBOM, 1970. 
Disponível em http://www.letras.ufmg.br/poslit

reiteradas desde el título. Se busca una coherencia estructural para el relato de las muertes de Ranquil: "De los que no entendieron bien, de los que murieron sin ver la aurora, de sacrificios ciegos y no retribuidos, de LOS QUE VAN QUEDANDO EN EL CAMINO también se hizo la revolución."

Al comienzo del drama, se entrega una serie de indicaciones de montaje que apuntan a una coherencia sígnica y metodológica. Por ejemplo, la iluminación es la encargada de marcar la diferencia entre las escenas de los vivos y de los muertos o de situar deícticamente al espectador en una determinada atmósfera; la escenografía, el vestuario y la música contribuyen a precisar las características del espacio (herramientas, utensilios) o de las personas (vestuario cordillerano).

La palabra mamá en relación a Lorenza es un deíctico marcador y diferenciador del presente en relación al tiempo de los muertos. Lo mismo que la compañía de Juanucho, primer receptor del relato. Por el carácter rural de la pieza, se adjunta al texto un vocabulario con el fin de aclarar giros y estructuras propias del espacio campesino chileno. Este lenguaje se mezcla en la pieza con otro de carácter político socialista.

La obra gira en torno a Lorenza que relata a su sobrino Juanucho la matanza histórica de Ranquil (1934) guiada por un profesor que hace las veces de "intelectual-orgánico" (entendido en el sentido de Gramsci). Ellos piden la tierra, que les fue concedida por el gobierno anterior, a quienes hoy se la han usurpado (los que detentan el poder y el dinero en la zona). Sus recuerdos se concretizan en acción en el escenario, produciéndose una simultaneidad temporal entre el pasado y el presente; ésta es confirmada con una marcha hacia Santiago de nuevos campesinos en pos de las mismas reivindicaciones. La pieza está enfocada desde la macro problemática social en defensa de la tierra; las situaciones personales (el amor de Lorenza y Rogelio o de Dominga y el profesor) se diluyen en este enfoque globalizante. La canción final busca reafirmar didácticamente el compromiso social del espectador.

\section{Lautaro}

Esta pieza fue publicada en 1982 con el subtítulo Epopeya del pueblo mapuche y surgió, según la autora, a pedido de un amigo suyo de la familia
Painemal con el "fin de apoyarlos en la lucha de hoy".?

Esta incursión de Isidora Aguirre en diversos contextos sociales utilizando la observación adquiere un especial connotación en esta pieza; puesto que une el discurso histórico con los discursos literario y oral, sin establecer entre ellos las distinciones jerárquicas propias de la literatura canónica. El sólo hecho de partir de ambas voces e íconos, Valdivia y Lautaro, posibilita la subversión histórica y social. La creación, como decía anteriormente, fue estructurada en base a estos grandes héroes de la conquista chilena. El primero nació, según Isidora Aguirre, de su contacto con el pueblo mapuche y el segundo de las cartas enviadas por Valdivia al Rey de España. El conjunto chileno los jaivas creó la música para el montaje de grupo PROTECHI (Producciones Teatrales Chilenas) en 1982. Este montaje utilizó un gran despliegue de actores, que jugaron con sus cuerpos y la música para crear la ambientación y el relato de la guerra de Arauco.

El lenguaje de la obra es esencialmente poético e incorpora dentro del macrosigno las sensibilidades, ficcionalizadas por la historia, la leyenda y la literatura, de Lautaro y Valdivia. Son caracteres con vida interior, a diferencia de los personajes de Los que van quedando en el camino, estos luchan desde sí mismos. Esta característica se patentiza en los gestos internos nacidos de sus emociones (la larga mirada que dieron en el campo de batalla), en sus esperanzas (de dominio y libertad) y en el objetivo de su lucha (Arauco). Esta situación no se logra de la misma manera con los otros personajes que son menos complejos y responden más bien a tipos sicológicos: Las mujeres: las compañeras y los mensajeros: los graciosos al modo del teatro español.

El paralelo, que el espectador percibe, entre la lucha histórica relatada y la que esta viviendo el pueblo chileno en 1982 es la contextualización buscada en el momento del montaje. Esto se logra a través de la imagen del pueblo araucano que resistió 300 años y del signo de lucha que trasmite la imagen de Lautaro, ambos elementos graficados en las voces y en la música que al final de la obra van dando testimonio de su realidad simbólica:

- Lautaro, estás aquí

- Lautaro, estoy contigo

- Lautaro, estás conmigo

- Estás en mí, Lautaro...

No cambiaré, mi destino es resistir

9. AGUIRRE, 1982, p. 8. 


\section{Retablo de Yumbel}

Esta obra fue estrenada en 1986 por el Teatro El Rostro en Concepción y publicada en 1987 por LAR, obteniendo este mismo año ei Premio Casa de las Américas. La obra está dedicada a José Manuel Parada, asesinado en 1985 por la dictadura militar chilena.

La motivación externa al hecho escritural proviene de descubrimiento en el pueblo sureño de Yumbel de los restos de 19 dirigentes, dados hasta esa fecha por detenidos-desaparecidos y realmente asesinados el 11 de septiembre de 1973. La acción se sitúa en la plaza de Yumbel en 1980, en vísperas de la fiesta de San Sebastián, patrono de dicha ciudad. La situación dramática establece un paralelo entre el sufrimiento de San Sebastián a manos de los romanos y el de los chilenos a manos de la dictadura. Técnicamente podemos hablar de una experiencia que une lo metateatral y la simultaneidad histórica. Este último aspecto es recurrente en la escritura de Isidora Aguirre, se trata de producir un macrosigno que una en la diacronía los momentos históricos donde se hace patente la lucha de los desposeídos, de los que no tiene acceso al poder.

La metodología brechtiana se vuelve a hacer presente en esta obra con marchas, coros, canciones y banderas que pretenden clarificar la situación de los detenidos-desaparecidos y de sus familias. Se reivindica, a través de la imagen de San Sebastián, el papel de los cristianos en la lucha social. Postulo que se trata de una reivindicación, pues en las obras anteriores de Isidora Aguirre generalmente había aparecido la religión junto al poder (Los que van quedando en el camino). En cambio, ahora, aparece defendiendo los derechos humanos.

La pieza cuenta con diálogos cultos, expresados tanto en verso como en prosa; según cual sea el objetivo de cada discurso: comunicar, convencer, emocionar, etc. El lenguaje, en su conjunto, tiene un carácter

\section{Disponível em http://www.letras.ufmg.br/poslit}

marcadamente subjetivo. La intención es involucrar al espectador, por lo tanto podemos sostener que no hay pretensión de objetividad, sino de persuasión ilocutoria.

Las mujeres en esta obra son las madres o mujeres de los héroes desaparecidos y su papel es recordarlos como si estuvieses vivos (rol que en el referente real cumplieron las agrupaciones de detenidos y desaparecidos, conformadas prioritariamente por mujeres). Esta situación llega en la obra y en la realidad a anular la existencia personal de estas mujeres en función de encontrar los restos del ser amado. Este hecho me parece de especial relevancia, pues aborda un tópico ya recurrente: la mujer como productora de historia subyacente, movilizadora oculta de las dinámicas sociales y políticas.

Diálogos de fin de siglo

La Editorial Torsegel edita en 1989 esta obra, que anteriormente había sido representada por ICTUS. La pieza presenta una problemática candente en el período dictatorial, su macro-objetivo es realizar una desmistificación de Chile como país de tradición eminentemente democrática, para eso reconstruye el contexto del suicidio de Balmaceda, Presidente constitucional en 1981, año de su muerte. Agustín Letelier plantea:

En esta línea tiene especial importancia el diálogo que refuta con datos muy concretos, la afirmación constantemente repetida de que los chilenos somos los ingleses de sudamérica, pueblo moderado y respetuoso de las instituciones.

Este montaje emplea cabezones al modo del teatro de Gran Guiñol y su escenografía está basada en signos dados por la luz o por elementos que tipifican lugares o épocas. De este modo, estos lenguajes plásticos adquieren especial importancia en la producción del macrosigno teatral. El conflicto central de esta pieza traspasa lo individual e incluso lo histórico; pues gira en torno a una cuestión de orden filosófico: la inutilidad e inconstitucionalidad de una guerra nacida en los abusos de poder. El macrosigno de esta pieza se intensifica en la imagen final de Felipe (el 
hijastro muerto de Rosario), que se comunica desde el más allá para denunciar el absurdo de la guerra.

Las mujeres, en esta pieza, tienen un papel más relevante que en las producciones anteriores: Rosario se rebela ante lo que siente como un acoso de los conservadores a Balmaceda negándose al contacto físico con su marido; Amanda (su sobrina) decide pintar e inclusive presentar un desnudo de sí misma en una exposición, también opta por hacer el amor sin casarse. Ambas pertenecen a la clase alta; los personajes femeninos de clase baja sólo se manifiestan como madres (Corina, la sirvienta de la casa de Rosario). Reafirmando esta tesis podemos recordar a la Guatona Romilia de Los que van quedando en el camino.

Los problemas de esta obra dicen relación con la estructura dramática, que se ve forzada a producir una determinada conceptualización: la imagen de Felipe muerto comunicándose con su familia no es coherente con la lógica de la pieza, con el código sígnico establecido desde el comienzo de la obra. Se trata de priorizar el contenido a la forma o la forma al contenido, vieja dicotomía que Isidora Aguirre en otras piezas logró resolver.

\section{A modo de conclusión}

Hablar de las obras de Isidora Aguirre nos remite a la evolución de la dramaturgia contemporánea chilena. Sus piezas han reaccionado a contextos diversos - surgimiento del teatro experimental universitario (1941), abertura hacia las ideas sociales (1960), dictadura militar (1973) con versatilidad, pero también con una cierta constancia determinada fundamentalmente por su preocupación con el referente. La problemática del poder es el eje estructurante de sus creaciones, y es esto lo que genera la contigencia político-social de los conflictos presentados. Al modo de la brasileña Consuelo de Castro o de la argentina Griselda Gambaro, su escritura se centra en lo que el feminismo norteamericano ha llamado "lo público" y el feminismo hispanoamericano "la calle" en oposición a "lo privado"o a "la casa". En definitiva, a aquel espacio, históricamente, vedado a la mujer. La enunciación de Isidora Aguirre se apropia del centro. No se trata de afirmar que éste sea el único medio de desconstruir la relación entre el margen y el centro, pues sabemos de otras escritoras que lo hacen desde la cocina (Laura Esquivel); de lo que se trata es de reconocer como posible el camino elegido por Isidora Aguirre.
Si bien hemos dicho que la estructura del lenguaje en las obras dramáticas de esta escritora se caracteriza por lo andrógeno, me parece fundamental especificar que esto no significa que la problemática genéricasexual no esté presente en sus textos. De hecho, la profundidad de algunos de sus personajes femeninos implica un trabajo con una realidad observada, pero principalmente conocida interiormente. Se establecen expectativas que nacen de vivencias propiamente femeninas. Así Rosario y su sobrina en Diálogos de fin de siglo se rebelan utizando su cuerpo. Sabemos que el cuerpo femenino desde siempre ha sido objeto del deseo - pecaminoso o aceptado - y por eso mismo potencialmente subversivo.

Finalmente, me cabe reconocer el papel desempeñado por escritoras como Isidora Aguirre, quienes al interior de un discurso hegemónicamente masculino (dramaturgas con montajes y libros publicados no fueron ni siquiera mencionadas por las historias oficiales del teatro chileno: por ejemplo, Luisa Zanelli López y Ana Neves) fueron capaces y lo siguen siendo de sostener la palabra con calidad estética. Isidora Aguirre ha abierto un camino para el surgimiento en el teatro chileno de esa voz de mujer hasta hoy oculta o silenciada.

\section{REFEREREENCIAS BIBLOGRÁFICAS}

AGUIRRE, Isidoro. The Woman Ploywright os Sociol Political Critic. Documento sin editor leido en el Congreso de Dramoturgio Femenino realizodo en Buffolo, 198B.

AGUIRRE, Isidora . Entrevisto personol reolizoda en 1990 AGUIIRRE, Corolinn, Teatro chileno odtual. Sontiogo. Zig Zog, 1970. SOLORZANO, Corlas. Prólogo. In AGUIRRE, Isodoro, Los papeleros. Santiogo: Ed. Torsegel, 1986 AGUIRRE, Isidoro. Los papeleros. Santiago: Ed. Torsegel, 1986. TEITELBOM, Volodio. Prólogo. In AGUIRRE, Isodoro. Los que van quedanda en el camino. Sontiogo: Imprento Mueller, 1970. s.n. GUEVARA, Enesto. Epigrofe. Los que van quedondo en el comino. Santiago: Imprento Mueller, 1970. s.n. AGUIRRE, Isidoro. Prólogo. Lautoro. Santiogo: Noscimento, 1982

GURR, sidora. Lautoro. In AGUIRRE, Isadora. Santiogo: Nascimento, 1982.

ETELLER, Agustín. Prólogo. Diólogos de fin de siglo. Santioga: Ed. Torsegel, 1986. 